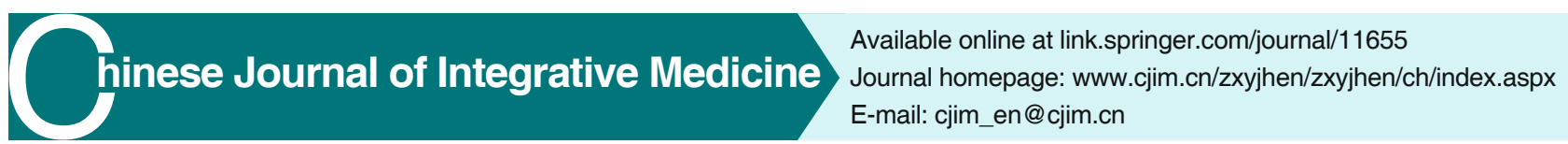

Hot Topic

\title{
Traditional Chinese and Western Medicines Jointly Beat COVID-19 Pandemic*
}

\author{
QING Guang-chao ${ }^{1,2}$, ZHANG Hong ${ }^{1,2}$, BAI Yang ${ }^{1}$, and LUO Yang ${ }^{1,2}$
}

The novel coronavirus disease (COVID-19) infection has been spreading for more than 2 months since it broke out early $2020 .{ }^{(1)}$ The alarming levels of spread and severity have made this virus characterized as a pandemic which has been affecting at least 200 countries, areas or territories around the world. And 1051,635 cases and 56,985 deaths were confirmed by 10:00 CET April 4, 2020. ${ }^{(2)}$ So far, it is encouraging to note that the outbreak of COVID-19 in China has been basically contained and more than 77,200 patients in China have been cured after a series of treatments, ${ }^{(3)}$ which suggests that patients can be cured through therapy even though there is an absence of specific medications and vaccines.

Vaccines and targeted drugs are most effective in preventing and combating infectious diseases. However, developing such vaccines is particularly timeconsuming and arduous, and the long-term side effects of new medicine could also be a concern. Some recent studies and clinical data have demonstrated that among the limited therapies, Chinese medicine (CM), together with Western medicine (WM), plays an important role in halting the progress of the disease and promoting the recovery of patients in the absence of targeted drugs. ${ }^{(4,5)}$ With discreet assessment, integrated CM and WM treatment with clear and constantly updated prescriptions has been approved for clinical use since the third version of the Handbook of Prevention and Treatment of the Pneumonia Caused by the Novel Coronavirus (2019-nCoV), which was issued by the Chinese authorities. ${ }^{(6)}$ The latest handbook recommended different $\mathrm{CM}$ and WM prescriptions for diversified categories of COVID-19 cases including mild, moderate, severe, critical, convalescent, and suspected (Appendixes 1 and 2). ${ }^{(7)}$

Recent studies have demonstrated that treatment with integrated $\mathrm{CM}$ and WM can significantly alleviate fever, cough, and other clinical symptoms. A clinical observation showed that the patients' indexes such as serum amyloid $A$, lymphocyte percentage, creatine kinase isoenzyme $\mathrm{MB}$, alanine transaminase, aspartate transaminase, and blood urea nitrogen in the integrated therapy group recovered faster than those treated with WM only. ${ }^{(8)}$ Combined administration of Toujie Quwen Granules (透解祛瘟颗粒, prepared from 16 CMs such as Fructus Forsythiae, Pseudobulbus Cremastrae, Flos Lonicerae, Radix Scutellariae, Folium Isatidis, etc.) and arbidol up-regulated the expressions of peripheral blood $\mathrm{CD}^{+} / \mathrm{CD}^{+}$and absolute value of lymphocyte in 37 mild COVID-19 patients while arbidol alone not, indicating the positive function of integrated therapy in regulating the balance of immune cells and promoting the recovery of immune function. ${ }^{(9)}$ In another study, the integrated therapy showed a substantial increase in the rate of hospital discharge and reduction in the rate of deterioration. ${ }^{(10)}$

In addition, inflammatory exudation and inflammatory storm associated with COVID-19 often result in acute lung injury, which subsequently causes severe respiratory failure and even death. Antibody drugs like tocilizumab can neutralize interleukin- 6 directly, thus effectively alleviating cytokine storms, but they are too expensive to be widely adopted. ${ }^{(11)}$ In comparison, the $\mathrm{CM}$ therapy which is relatively low-cost, can considerably relieve the inflammatory reaction as well through affecting the lymphatic system to modulate the patient's immune response. ${ }^{(12)}$ Therefore, proper integration

(C)The Chinese Journal of Integrated Traditional and Western Medicine Press and Springer-Verlag GmbH Germany, part of Springer Nature 2020

*Supported by the Fundamental Research Funds for the Central Universities (No. 2020CDJYGRH-YJ05), China

1. Center of Smart Laboratory and Molecular Medicine, Medical School of Chongqing University, Chongqing (400044), China; 2. Key Laboratory of Biorheological Science and Technology of Ministry of Education, School of Bioengineering, Chongqing University, Chongqing (400044), China

Correspondence to: Prof. LUO Yang, E-mail: luoy@cqu.edu.cn DOI: https://doi.org/10.1007/s11655-020-3095-6 
of the two therapies may make the treatment more economical for patients. This strategy is also suitable for regulating the activation of classic renin-angiotensin system regulatory pathway, which is activated when 2019-nCoV binds with angiotensin converting enzyme 2 receptor and is responsible for multiple organ injuries. ${ }^{(13)} A$ comparative study on 710 cases jointly conducted by over 30 hospitals showed that combining regular treatment with Xuebijing Injection (血必净注射液, produced from $5 \mathrm{CMs}$ including Flos Carthami, Radix Paeoniae rubra, Rhizoma chuanxiong, Radix Angelicae sinensis, and Radix Salviae Miltiorrhizae) reduced the mortality rate of severe pneumonic patients by $8.8 \%$ and shortened intensive care unit hospitalization by 4 days. ${ }^{(14)}$ And a basic research performed on 156 patients at 32 hospitals recently also found that the injection has a certain antiviral effect in vitro that can inhibit inflammatory factors induced by 2019-nCoV infection. ${ }^{(15)}$ Although the clinical reports are limited and required to be confirmed by further studies, such treatment is a reliable alternative option.

While the therapeutic results are encouraging, the mechanisms and pathways through which CM works still need to be revealed. Side effects associated with the use of integrated CM and WM therapy should also be evaluated. In addition, the misuse of the integrated therapy by people who try to take precautions against COVID-19 infection should not be encouraged. Rational combination of CM and WM would benefit the treatment of diverse emerging or serious diseases in the near future.

\section{Conflict of Interest}

No conflict is declared.

\section{Author Contributions}

Luo $\mathrm{Y}$, Qing GC, and Zhang $\mathrm{H}$ conceived of the design and carried out the study. Qing $\mathrm{GC}$ and Zhang $\mathrm{H}$ undertook the literature review of historical evidence and wrote the manuscript. Luo $Y$ and Bai $Y$ provided important suggestions and revised the manuscript. Luo $Y$ supervised the study. All authors read and approved the final manuscript.

Electronic Supplementary Material: Supplementary material (Appendixes 1 and 2) is available in the online version of this article at http://dx.doi.org/10.1007/s11655-020-3095-6.

\section{REFERENCES}

1. Wang C, Horby PW, Hayden FG, Gao GF. A novel coronavirus outbreak of global health concern. Lancet 2020;395:470-473.

2. World Health Organization. Coronavirus disease 2019 (COVID-19) situation report-75. Accessed April 4, 2020. Available at https:// www.who.int/docs/default-source/coronaviruse/situationreports/20200404-sitrep-75-covid-19.pdf?sfvrsn=99251b2b_2

3. National Health Commission of the People's Republic of China. Update on the novel coronavirus pneumonia outbreak. Accessed April 4, 2020. Available at http://www.nhc.gov.cn/xcs/ yqtb/202004/4f4e36d54fc941d48f6ce6554514075e.shtml

4. Luo H, Tang QL, Shang YX, Liang SB, Yang M, Robinson N, et al. Can Chinese medicine be used for prevention of corona virus disease 2019 (COVID-19)? A review of historical classics, research evidence and current prevention programs. Chin $\mathrm{J}$ Integr Med 2020;26:243-250.

5. Yang $Q$, Sun $Q G$, Jiang $B, X u$ HJ, Luo $M$, Xie $P$, et al. Retrospective clinical study on treatment of COVID-2019 patients with integrated traditional Chinese and Western medicine. Chin Tradit Herbal Drugs (Chin) 2020:1-5. http://kns. cnki.net/kcms/detail/12.1108.R.20200413.1302.002.html

6. The State Council/The People's Republic of China. Handbook of prevention and treatment of the pneumonia caused by the novel coronavirus (2019-nCoV). Accessed April 4, 2020. Available at http://www.gov.cn/zhengce/zhengceku/2020-01/23/5471832/file s/106d59e45ac948ceb3cb12d400b8053c.pdf

7. Song $P$, Zhao LH, Li XY, Su JS, Jiang ZY, Song B, et al. Interpretation of TCM part in diagnosis and treatment protocol for COVID-19 (trial version 7). J Tradit Chin Med 2020:1-41. http:// kns.cnki.net/kcms/detail/11.2167.R.20200325.1623.002.html

8. Xia WG, An CQ, Zheng CJ, Zhang JX, Huang M, Wang Y, et al. Clinical observation on 34 patients with novel coronavirus pneumonia (COVID-19) treated with integrated traditional Chinese and Western medicine. J Tradit Chin Med (Chin) 2020;61:375-382.

9. Fu XX, Lin LP, Tan XH. Clinical study on 37 case of COVID-19 treated with integrated traditional Chinese and Western medicine. Tradit Chin Drug Res Clin Pharmacol (Chin) 2020:1-9. http://kns. cnki.net/kcms/detail/44.1308.R.20200319.1644.002.html

10. Cui HT, Li YT, Guo LY, Liu XG, Wang LS, Jia JW, et al. Traditional Chinese medicine for treatment of coronavirus disease 2019: a review. Tradit Med Res 2020;5:65-73.

11. Smolen JS, Beaulieu A, Rubbert-Roth A, Ramos-Remus C, Rovensky J, Alecock E, et al. Effect of interleukin-6 receptor inhibition with tocilizumab in patients with rheumatoid arthritis (OPTION study): a double-blind, placebo-controlled, randomised trial. Lancet 2008;371:987-997.

12. Liang $\mathrm{QQ}$, Chen $\mathrm{W}, \mathrm{Xu} \mathrm{H}$, Wang LL, Huang Y, Shi Y, et al. Explore the Effect of lymphatic system on acute lung injury caused by 2019$\mathrm{nCoV}$ and the potential mechanism of traditional chinese medicine therapy. World Sci Tech Mod Tradit Chin Med (Chin) 2020:1-8. http://kns.cnki.net/kcms/detail/11.5699.R.20200225.1653.002.html

13. Sun ML, Yang JM, Sun YP, Su GH. Inhibitors of RAS might be a good choice for the therapy of COVID-19 pneumonia. Chin J Tuberc Respir Dis (Chin) 2020;43:E014.

14. Song YL, Yao C, Yao YM, Han H, Zhao XD, Yu KJ, et al. Xuebijing Injection versus placebo for critically III patients with severe community-acquired pneumonia: a randomized controlled trial. Crit Care Med 2019;47:e735.

15. China Daily. Qiu Haibo: Xuebijing is effective in treating COVID-19. 2020/3/13. Accessed April 4, 2020. Available at http://cn.chinadaily. com.cn/a/202003/13/WS5e6b84f2a3107bb6b57a661d.html

(Accepted April 9, 2020; First Online May 2, 2020) Edited by YU Ming-zhu 